Pakistan Journal of Humanities and Social Sciences

October - December 2018, Volume 6, No. 4, Pages 526 - 543

\title{
Does Perceived Organizational Support influence the Employees Emotional labor? Moderating \& Mediating role of Emotional Intelligence
}

Zain Riaz ${ }^{1}$, Ayesha Arif ${ }^{2}$, Qasim Ali Nisar ${ }^{3}$, Shahzad Ali, Muhammad Sajjad Hussain $^{5}$

${ }^{1,2}$ MBA, Department of Management Sciences, University of Sargodha, Gujranwala Campus

${ }^{3,4}$ Department of Management Sciences, Superior University Lahore

${ }^{5} \mathrm{PhD}$ Candidate, School of Economics, Finance \& Banking, Universiti Utara Malaysia

Email: qasimalinisar@yahoo.com

\begin{abstract}
The services sector is an emerging sector that needs extensive research that can be helpful in managing employees' emotions. This study aims to examine the effect of perceived organizational support on emotional labor with the mediating role of emotional intelligence. Questionnaire survey method was adapted and data were collected from 370 employees of telecommunication sector through Simple Random Sampling Technique. Hypotheses were tested and analyzed by AMOS. Results showed that POS positively affects deep Acting but has a negative impact on surface acting. Results enlightened that emotional intelligence significantly mediates the relationship between perceived organizational support and emotional labor. The study also revealed the significant relationship of emotional labor and counterproductive work behavior. Surface acting positively and significantly effect on counterproductive work behavior whereas deep acting influence negatively on counterproductive work behavior. Findings also divulged that the relationship of emotional labor and counterproductive work behavior is significantly moderated by emotional intelligence.
\end{abstract}

Keywords: Perceived Organizational Support, Emotional Intelligence, Surface Acting, Deep Acting, Counter-productive Work Behavior.

\section{Introduction}

Employees feel privileged and demonstrate their commitment to achieving the goals (Wiesenberger et al., 1986, 2004; Eisenberger \& Rhoades, 2002). POS is a way to enhance the social sharing among individuals and organizations which is suggested by the organizational support theory. Emotions are a sentiment that inhabitant's familiarity construes, cogitate, articulate, and superintend (Mills \& Klein, 1988; Throats, 1989). 
Emotional Intelligence eases people to treat with every facet in a balanced way with great maturity. People by advanced of Emotional Intelligence boast reflective self-senses which help them to understand and recognize their (Muddassir \& Singh 2008). Emotional Intelligence comprises a set of abilities connected to the emotional dispensation of the information. Emotional Intelligence has also described the skills to perceive, garner information from and manage One's own and other's emotions (Jossey-Bass, 2004) Researchers used different kinds of terms to portray the concept of CWB. Therefore, CWB includes many actions like robbery, smash up and removal of assets, absenteeism, violent behavior and exploitation of organizational \& interpersonal interests (Spector \& Fox, 2005).

In addition, Social Exchange Theory presents the root for counterproductive work behavior. The present study intends at satisfying this scholastic gap in the literature and focal point going on the explore of the impact of Perceived Organizational Support on Emotional Labor and to inspect the mediating effect of Emotional Intelligence on the association of Perceived Organizational Support and Emotional Labor. Counterproductive Work Behavior compensated less attention to workers, this paper deliberates Counterproductive Work Behavior of employees, study influence factors employees. The intention of the study was to explore the impact of perceived organizational support (POS) on emotional labor (EL), by considering the mediating role of EI and to determine whether or not emotional intelligence (EI) sway the relationship between Emotional Labor and Perceived Organizational Support. The purpose is also to find out the relationship between EL \& CWB by considering the moderating role of EI. The review of literature display that organizational support generates positive behavioral outcomes. Strong evidence survives in the literature that POS boosts excellence of work life.

\section{Literature Review}

\section{A. Perceived Organizational Support}

Perceived Organizational Support means the feelings of employees about their organization's attitude towards their work, well-being \& socio-emotional need (Eisenberger et al., 1986). In addition, employees assure their hard work if they feel their esteem \& emotional needs are fulfilled (Armeli et al., 1998). In addition, several studies revealed different subvariables of "perceived organizational support". Four dimensions of "perceived organizational support" namely training, rewards, supervisory support and career development (Chou \& Robert, 2008; Eisenberger et al., 2002; Krishhan \& Mary, 2012; Barret et al., 2001). Talent and aptitude of employees is polished through training so they can 
contribute more towards the realization of ultimate mission of organization (Tharenou et al, 2007). According to Zia ur Rehman et al (2010) rewards represent the return of the efforts of staff members. Furthermore, the perception of workers that they are secured cared and their administration is concerned about their tasks referred to as supervisory support (Eisenberger et al, 2002). Through career development long-term survival of jobs of employees in an organization is ensured (Purcell, 2003). In past, only three dimensions were discussed for instance rewards, fairness and supervisory support (Wang et al, 2007; Simosi, 2012). Likewise, some researchers consider other unexplored dimensions like training and career development (Lee \& Brotheridge, 201; Kinman, 2009). In addition, researchers opined that employees feel privileged and demonstrate their commitment to achieve the goals (Rhoades \& Eisenberger, 2002). POS is way to enhance the social sharing among individuals and organizations which is suggested by the organizational support theory (Nisar et al., 2014)

\section{B. Emotional Labor}

Hochschild (1983) described that emotional labor is the performance of an organization which is change feelings or emotions to assemble organizational objectives. She describes Emotional labor as "the association feelings to generate promotion apparent facial and body language. Furthermore Mastracci, Guy \& Newman (2010) identified the relational work because it generates association among consumer \& employee. There are three dimensions these are: Deep Acting, Surface Acting and Genuine Emotion. Surface acting and deep Acting are two main points but genuine emotion now introduces (Diefendorff et al., 2005). Morris and Feldman had given third concept of Emotional Labor refers to "the planning, effort and control needed to convey organizational preferred emotion during interpersonal transaction". Deep Acting is the experienced emotions that try to find make parallel estimated demonstrate with the internal practice and behaviors by adaptable the appearance. Deep acting strategy is adapting inner feelings to convey appropriate emotion. Surface acting is (i.e. Suppression, Cote et al., 2013) to show fake emotion and hide real emotion for particular scenario. These both are compulsory and effective strategies which people adopt when they didn't display suitable emotions impulsively (Totterdell \& Holman, 2003; Grandey, 2003). Accurately displaying the emotions estimated by the organization is called Genuine Emotion (Nisar et al., 2017; Hayyat et al., 2017)

\section{Emotional Intelligence}

Emotional intelligence is described as "the capability to identify the sense of emotion and to motive and solve the problem on the base of them (Meyer, Allen \& Smith, 1993). The 
ability to recognize emotion, know yourself and your emotion and manage them (Meyer, Allen \& Smith, 1993). There are four dimensions of Emotional intelligence: "Self-Emotional Appraisal (SEA), Other Emotional Appraisal (OEA), Use of Emotion (UOE) and Regulation of Emotion (ROE)" (Wong \& Law, 2002; Mayer \& Solvy,1997). Self-Emotional Appraisal is separating prospective to expand his or her feelings and try to communicate these emotions. Self-Emotional Appraisal is also described as the ability of individuals to which is clear and recognize their emotions. Other Emotional Appraisal is regarding person's ability to think and distinguish the other feelings. Employees with high level of self-emotion appraisal suppose more aware of their feeling and emotions. Use of Emotion is the separate capability to use her or his emotion valuable task and personal performance. Use of emotion is further describe the ability of individual to use their emotion which for improvement in personal performance (Solvy \& Mayer, 1997). Regulation of Emotion is individual ability to manage her or his emotion in bad anger. It is encouraging intellectual growth, also refer to ability to be open to negative emotional state and positive emotional state. Johnson and Specter examine the association between EL and EI strategies it was examined that employee with elevated EI appreciate their and other consumer emotions and are superior talented to contract with EL and show better performance.

Emotional Intelligence supposes that main achievement of Psychology and it's prolonged to management studies owing to its great significance. Furthermore, the implementation of emotion in effective decision making (Nezad, 2013) One's own and other's emotions (Jossey-Bass, 2004)

\section{Counterproductive Work Behavior}

The term was presented as the deeds of members, working in an organizational setting, to damage the coworkers, consumers, buyers, higher authorities and the organization itself (Spector \& Fox, 2005). Furthermore, it is affirmed that the intention of employees not to follow the culture, orders of ruling authority of the organization and committing acts that injure the interests of the organization come under the model of counterproductive work behavior (Bennett \& Robinson, 2000). In addition, only stealing, ill-treatment and violence were discussed in the earlier researchers (Greenberg, 1990; Perlow \& Latham, 1993; Lehman \& Simpson, 1992; Haider et al. 2018; Imran et al., 2014). Moreover, the denial by employees to obey working hours and claim extra damages is organizational counterproductive work behavior (CWB-O), and the intention to harm other colleagues, misbehave with customers, 
making fun of others or teasing others is interpersonal counterproductive work behavior (CWB-I) (Robinson \& Bennett, 1995).

\section{E. Mediating Role of Emotional Intelligence}

Many studies found relationship between EI \& EL (Johnson \& Spector, 2007). Past researchers show that workers who have great level of emotional intelligence can manage themselves and other's emotions (Wong \& Law, 2002; Gosserand \& Diefendorff, 2005; Zhou \& George, 2003; Butt et al., 2017). Likewise, some researchers explored the link between POS and EL. The results of these studies explained that workers who perceive their organization supported and concerned for their wellbeing, are likely to work hard to attain what is expected from them. Consequently, employees feel to accomplish their responsibilities related to emotional labor. Many studies quoted the positive impact of POS on EL (Lou et al., 2010; Duke et al., 2009; Hur et al, 2013). Similarly, literature suggests that EI and EL are related to each other and EI strongly influences EL. Furthermore, the way an organization handles the employees puts the responsibility on the shoulders of employees to accomplish the organizational objectives (Ahmad-Mughal et al., 2017). Thus, POS is a drive that motivates workers (Liao et al., 2009). Employees with high level of motivation perform their job wholeheartedly and try to manage customers the way their organization and job demands (Kahn, 1990). Moreover, encouraging and affirmative deeds done by organization for the wellbeing of employees build strong positive relationships between employer and employees (Konovsky \& Pugh, 1994), due to this behavior employees tend to pay back the same response to the employer (Eisenberger et al., 1986). In the same sense, Lambert (2000) opinioned that employees give the same attention to the orders and objectives of employers which they have taken from them. Especially in those kinds of jobs where employee have to directly deal with customers, employees tend to shape EL accordingly. According to some researchers, the feeling of responsibility that arises in an employee because of positive POS comes under the concept of social exchange theory. Similarly, more support from organization's side make employees to put more efforts. The more the POS, the more efforts employees' will make. Low level of POS makes employees to put fewer efforts (Eisenberger et al., 2001). Hence, employees are likely to use less emotional intelligence to understand organizational requirements (Rhoades et al., 2001).

Researchers explain the mediating role of EI. Emotional intelligence only helps the individuals to complete their own tasks but not the organizational tasks (Hsu B.F et al 2010). Similarly, employers can only motivate the employees but can't make them to use emotional 
intelligence (Goleman, 2001). Likewise, in collectivist countries like Pakistan, group performance is focused (Hofstede, 1984). In collectivist countries, individual's performance enhances the group performance and emotional intelligence contributes to it (Mayer \& Salovey, 1993; Singh, 2010). Lack of EI will make employees to put fewer efforts. Lower the EI less will be the emotions management (Caruso \& Wolfe, 2001). On the other hand, employees having high level of EI manage their emotions better that are beneficial for the organization (Westbrook \& Crolley-Simic, 2012).

\section{F. Moderating role of Emotional Intelligence}

"Emotional intelligence is a category of capability which inhabitants utilize to efficiently emotions to handle their actions and thoughts (Salovey, 1999). Leaders' emotional intelligence in society, that is refers to capability which leaders' presentation elsewhere of lenient, manage their possess, management and valuation of others' (especially subsidiary) psychology and performance with attitude associated in the procedure of work and social communication. Specially, for management of reputed emotional intelligence, it's easier to comprehend in addition to manage their own and member of staffs' behaviors' and emotions and exist capable toward communicate and support employees to fault the difficulty in progression of work. When employees prefer surface acting in effective process, level of their psychosomatic exhaustion will exist superior. The leadership of the superior emotional intelligence will distinguish their low energy, regulate the mood and improve their mental exhaustion to diminish their counterproductive work behavior. Then employees by employment choose deep acting, superior emotional intelligence headship resolve distinguish employees' genuineness and devotion; they will commend and care about them appropriate. Considerate and commend from management will also hold back employees 'counterproductive work behavior. Conversely, honored that have thick emotional intelligence cannot experience employees' emotions appropriate and precisely, so the mediation will be damaged and persuasion will be tiny. Consequently, the understudy attaches significant' emotional intelligence as the moderator to investigate the interactive belongings of emotional labor and managers' emotional intelligence on counterproductive work behavior in service industry."

\section{G. Emotional Labor and CWB}

Counterproductive work behavior can be abolished through Psychological Capital. Employees with high psychological capital are less prone to Counterproductive Work Behavior. On the other hand, low psychological capital motivates employees to indulge in 
Counterproductive Work Behavior. The mediation of psychological capital between surface acting and Counterproductive Work Behavior is not momentous. The mediation function of psychological capital connecting Deep Acting and Counterproductive Work Behavior is important. Employees with higher level of psychological capital are involved in deep acting and do not show Counterproductive Work Behavior. Furthermore, low psychological capital employees lean towards Surface Acting and still be prone to be involved in Counterproductive Work Behavior. The moderation of leaders' emotional intelligence is not significant between the relation of Counterproductive Work Behavior and Surface Acting. The moderating position of leaders' emotional intelligence connecting Counterproductive Work Behavior and deep acting is important. Furthermore, Deep Acting relates negatively with the Counterproductive Work Behavior in lofty emotional intelligence leadership organization and vice versa.

Furthermore, In the organizations with the higher level of emotional intelligence, deep acting has a negative result on the Counterproductive Work Behavior, the higher the leaders' emotional intelligence, greater the propensity to perform Counterproductive Work Behavior and deep acting. Furthermore, the leadership must at all times be concerned about the staff. Extra attention and will increase the chances for them to build their business objectives as their conscientiousness, thus to decrease the possibility of employees' Counterproductive Work Behavior and to encourage the company effective, healthy and sustainable improvement.

\section{H. Theoretical Framework}

Current study intends to fulfill the gap in the literature. The aim is to explore the impact of Perceived Organizational Support on Emotional Labor and to inspect the mediating effect of Emotional Intelligence on the association of Perceived Organizational Support and Emotional Labor. This study also finds the relationship of EL and CWB by the moderation of EI.

\section{J. Hypotheses}

H1: POS significantly influence the EL.

H2: EI significantly mediates the relationship between POS and EL.

H3: Surface Acting has positive significant impact on CWB.

H4: Deep acting negatively \& significantly affects CWB.

H5: Emotional Intelligence moderates the relationship between EI \& CWB. 
Figure 1

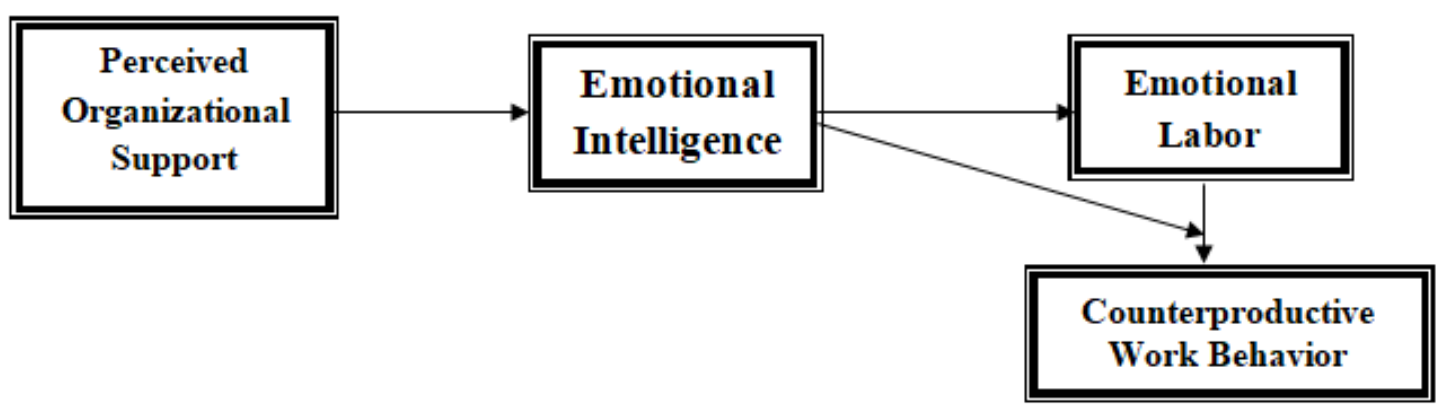

\section{Methodology}

This research is conducted to check out the relationship among the perceived organizational support and emotional labor and also the impact of emotional labor on counterproductive work behavior. Emotional intelligence is considered as mediating moderator. The study is supported by previous researchers and is a type of quantitative one.

\section{A. Questionnaire Design}

To collect the data survey method was adopted. As this is a quantitative study that is why questionnaire is used to collect and measure the responses of the respondents. Our questionnaire consists of two sections. The first section is about the demographics of respondents including the age, gender, education, nature of employment and length of services. Nominal scale is used to measure the profile. In the second section, the response is asked about the variables of research i.e perceived organizational support, emotional labor, emotional intelligence and counterproductive work behavior.

\section{B. Sampling}

For sample selection, the employees working in telecommunications sector were selected as the target population. According to the thumb rule of Hair et al (2010), sample size can be selected by multiplying the number of items in scales by 10 so our sample size is 370. Data was collected by applying simple random sampling technique because most of the studies in social sciences adapted this technique.

\section{Measures}

The relationship is verified by applying the survey method and for that questionnaire was designed. Scales used to measure the variables are adopted from previous studies.

\section{Perceived organizational support}

Perceived organizational support is measured by adopting 7 items scale developed by Eisenberger, Huntington, Hutchison \& Sowa (1986). The scale widely adopted to measure the perceived organizational support. 


\section{Emotional Intelligence}

To measure the emotional intelligence 16 item scale of (Wong \& Law, 2002) was adopted.

\section{Emotional Labor}

Items measuring surface and deep acting came from the Emotional Labour Scale (Brotheridge\&Lee, 1998).

\section{Counterproductive work behavior}

8 items scale was adopted from Reeshad S. Dala et al. (2009) to measure the responses regarding counterproductive work behavior.

\section{Data Collection Method}

A list of franchises and offices of telecommunication sector was collected from different websites. First, we met their General Managers and shared our study purpose. They encouraged their employees to take part in the survey. Questionnaires were distributed among employees. Time of one week was given to them. Out of 180 questionnaires, 150 were received back.

\section{E. Demographics}

Data were collected from 150 employees working in the telecommunication sector. Out of all the employees, $62 \%$ was male and $38 \%$ was females. Likewise, $77 \%, 20 \%, 2 \%$ and $1 \%$ employees were of the age of up to $25,26-45,46-55$ and 56+ respectively. Moreover, 43.3\%, 48.7\%, 8\% and 1\% have done Bachelor's, Master's, Ph.D. and Others respectively. Following to these $15.3 \%$ employees are contractual, $20 \%$ are permanent and $64.7 \%$ are from others. $64.7 \%$ respondents have up to 1-year length of service and $26 \%, 6.7 \%$ and $2.7 \%$ respondents have 2-5 years, 5-10 and 10+ years length of service in the telecommunication sector.

\section{Results and Findings}

\section{A. Descriptive Statistics}

"The above-mentioned table is representing the descriptive statistics, reliability and Pearson correlation among all understudies' variables. The highest correlation existed perceived organizational support and deep acting which is valued at 0.506. It reflects the positive relationship between perceived organizational support and deep acting with a moderate standard deviation. All other variables named as perceived organizational support, Surface acting, Deep acting, Emotional Intelligence and CWB are also significantly correlated with each other. The mean values are showing the trend of responses that most of them lie 
towards agreeableness. Results indicate that alpha values for all variables are under acceptable range to prove data reliability."

Table 1

\begin{tabular}{|l|l|l|l|l|l|l|l|l|}
\hline & Construct & Mean & SD & $\alpha$ & 1 & 2 & 3 & 4 \\
\hline 1 & Perceived Organizational Support & 3.96 & .463 & .72 & -- & & & \\
\hline 2 & Surface Acting & 3.63 & .828 & .79 & $-.313^{*}$ & -- & & \\
\hline 3 & Deep Acting & 3.75 & .737 & .85 & $.506^{* *}$ & $.414^{* *}$ & -- & \\
\hline 4 & Emotional intelligence & 4.04 & .366 & .83 & $-.224^{*}$ & -.210 & -.207 & -- \\
\hline 5 & Counterproductive Work Behavior & 2.02 & .515 & .75 & & & & \\
\hline
\end{tabular}

\section{B. Factor Loadings}

\section{Table 2}

Factor loading of all the items of understudied variables is above 0.7 so, none of the items is deleted.

\begin{tabular}{|l|l|l|}
\hline Constructs & Items & Factor Loadings \\
\hline Emotional Intelligence & 16 & $\begin{array}{l}.781, .521, .786, .739, .705, .835, .708, .813, .869, .865, \\
.784, .818, .842, .711, .872, .759\end{array}$ \\
\hline CWB & & $.728, .892, .837, .763, .784, .857, .892, .741$ \\
\hline POS & 8 & $.761, .821, .786, .739, .745, .849, .732$, \\
\hline SA & 7 & $.783, .902, .782$ \\
\hline DA & 3 & $712, .912, .892$ \\
\hline
\end{tabular}

\section{Fit Indices}

Table 3

\begin{tabular}{|c|c|c|}
\hline Fit Indices & CFA & SEM \\
\hline Chi-square/df & 2.02 & 2.01 \\
\hline GFI & 0.92 & 0.93 \\
\hline AGFI & 0.88 & 0.88 \\
\hline CFI & 0.94 & 0.95 \\
\hline RMSEA & 0.08 & 0.07 \\
\hline
\end{tabular}

"Table 3 is presenting the results of model fitness from both CFA and SEM dimensions. Goodness of fit index is given at the first place which represents the variance covariance matrix and as its value is greater than 0.90 so it is declaring a good fit of the model. AGFI is adjusted GFI whose value is greater than 0.8 which is quite good to prove that model is good fit. CFI is representing the comparative fit index which is showing more realistic values that are proving that model is near to absolute fit due to greater than 0.9 value. RMSEA is root mean square error of approximation whose value is lesser than 0.10 so that is also indicating the good fitness of model. The values of NFI, PGFI and PNFI are also lies in 
good range so they are also contributing that the understudy model is quite fit in statistical terms."

\section{Structural Model Regression Weights}

Table 4

\begin{tabular}{|l|l|l|l|l|l|l|}
\hline & & & Estimate & S.E. & C.R. & P \\
\hline Surface Acting & $<---$ & $\begin{array}{l}\text { Perceived Organizational } \\
\text { Support }\end{array}$ & -.523 & .082 & 6.37 & .01 \\
\hline Deep Acting & $<---$ & $\begin{array}{l}\text { Perceived Organizational } \\
\text { Support }\end{array}$ & .416 & .113 & 3.68 & .03 \\
\hline Surface Acting & $<---$ & Emotional Intelligence & -.316 & -.141 & 2.24 & .04 \\
\hline Deep Acting & & Emotional Intelligence & .368 & .074 & 4.97 & .02 \\
\hline $\begin{array}{l}\text { Counterproductive } \\
\text { Work Behavior }\end{array}$ & $<---$ & Surface Acting & .431 & .078 & 5.52 & .03 \\
\hline $\begin{array}{l}\text { Counterproductive } \\
\text { Work Behavior }\end{array}$ & $<---$ & Deep Acting & -.465 & .09 & 5.16 & .02 \\
\hline
\end{tabular}

Table 4 indicated the regression weighted for all under study relationships. Findings revealed that perceived organizational support has negative and significant association with surface acting $(b=-.523 ; \mathrm{p}<0.05)$ and positive relationship with deep acting $(b=.416 ; \mathrm{p}<0.05)$ and supported to H1 that POS has significant relationship with emotional labor. Moreover, findings also indicated that surface acting has a significant and positive relationship with counterproductive work behaviors $(b=.431 ; \mathrm{p}<0.05)$ and $\mathrm{H} 3$ is accepted. Similarly, deep acting also significantly and negatively influence the counterproductive work behaviors $(b=-$ $.465 ; \mathrm{p}<0.05)$ and therefore $\mathrm{H} 4$ also accepted.

\section{E. EM Mediation}

\begin{tabular}{|l|l|l|l|}
\hline Independent Variables & Effects & Surface Acting & Deep Acting \\
\hline \multirow{4}{*}{ Perceived Organizational Support } & Direct Effect & $-.526^{*}$ & $.416^{*}$ \\
\cline { 2 - 4 } & Indirect Effect & $-.573^{*}$ & $.483^{*}$ \\
\cline { 2 - 4 } & Total Effect & $-.467^{*}$ & $.521^{*}$ \\
\hline
\end{tabular}

Note: Mediating Variable: Emotional Intelligence

The hypothesis being illustrated would be tested through the SEM mediation analysis. The direct effect of POS on SA and DA is -0.526 and 0.416 respectively. Similarly, total effects -0.467 and 0.521 respectively and all four paths are significant which indicated that emotional intelligence partially and significantly mediates between POS, SA, and DA. H2 is accepted as emotional intelligence mediates the relationship between POS and emotional labor being significantly true and valid. 


\section{F. Moderation Analysis}

The moderating role of emotional intelligence on the relationship between surface acting \& counterproductive work behavior are as under;

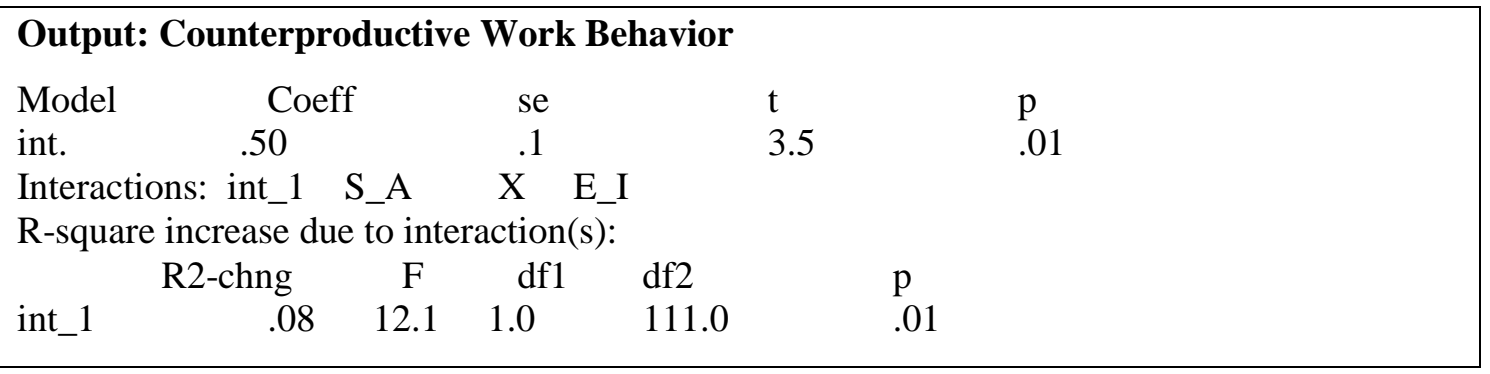

Finding revealed that interaction term is significant at $\mathrm{p}<0.05$ and there is a change in $\mathrm{R}^{2}$ (5\%) which proved that emotional intelligence significantly moderates on the relationship of surface acting and counterproductive work behavior. The statistics values as shown in above table of moderation analysis provide supportive results for the moderating role emotional intelligence between surface acting and counterproductive work behavior. Results illustrated that in the presence of emotional intelligence, the relationship between surface acting and counterproductive work behavior become weak.

The moderating role of emotional intelligence on the relationship between Deep acting \& counterproductive work behavior are as under;

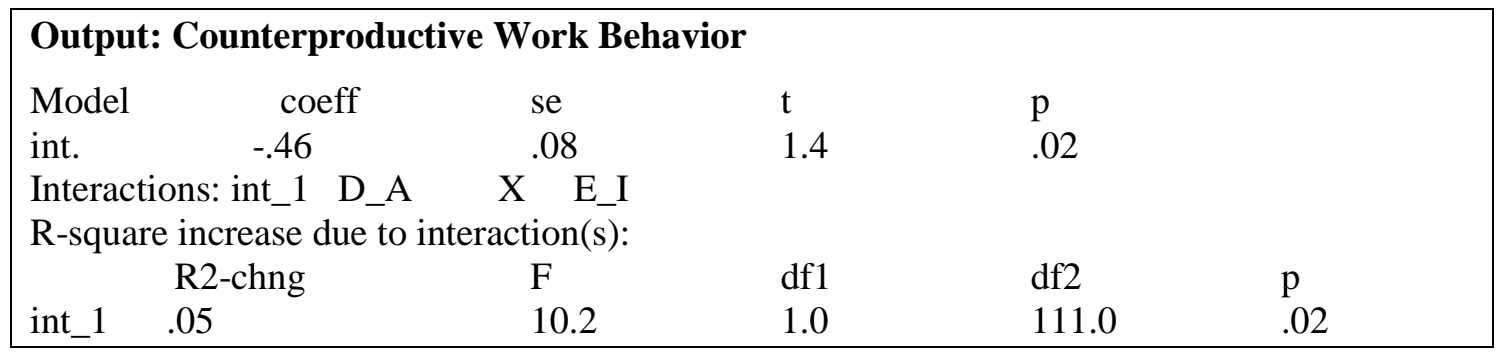

The model outcome showed that interaction term is significant at $\mathrm{p}<0.05$ and there is a change in $\mathrm{R}^{2}(5 \%)$ which proved that emotional intelligence significantly moderates on the relationship of deep acting and counterproductive work behavior. The statistics values as shown in above table of moderation analysis provide supportive results for the moderating role emotional intelligence between deep acting and counterproductive work behavior. Results illustrated that in the presence of emotional intelligence, the relationship between deep acting and counterproductive work behavior become strong. 


\section{Discussion and Conclusion}

The purpose of the study is to inspect the impact of perceived organizational support on emotional labor by considering the mediating role of Emotional Intelligence. The purpose was to know the level to which Emotional Labor influences the Counterproductive Work Behavior by considering the moderating role of Emotional Intelligence. Questionnaire survey method was adopted and data was collected from 150 respondents working in the telecommunication sector. The results showed that when an organization is concerned about the employees then employees will try to change their inner feelings to achieve organizational objectives. If the employees are emotionally intelligent then they will mold their emotions (Duke et al., 2009, Konovsky \& Pugh, 1994; Liao et al., 2009; Hur et al., 2013). On the other side, if the employees change their internal emotions, not only outer emotions, then they will not harm their organization.

Findings proved that perceived organizational support has significant and positive association with deep acting and negative relationship with surface acting and supported to H1 and backed by previous studies (Lou et al., 2010; Duke et al., 2009; Hur et al, 2013; Liao et al., 2009; Kahn, 1990; Eisenberger et al., 2001; Rhoades et al., 2001). Moreover, findings also revealed that emotional intelligence mediates the relationship between POS and EL and supported to H2. These findings are highly supported by previous studies (Hsu B.F et al 2010; Goleman, 2001; Mayer \& Salovey, 1993; Singh, 2010; Caruso \& Wolfe, 2001; Westbrook \& Crolley-Simic, 2012; Mishra, 2013). It means that if employees are emotionally intelligent, they can manage their emotions in a better way while interacting with others. The study also proposed that surface acting has a significant and positive relationship while deep acting has a negative association with counterproductive work behaviors and supported to H3 \& H4. Moreover, emotional intelligence also moderates on the relation of emotional labor and counterproductive work behaviors and supported to H5. Employees with a high level of emotional intelligence can modify their inner feeling and emotions according to the situation due to which they can tackle counterproductive work behaviors in a better way. This research highlighted effective support to employees and management of their emotions will lead to positive performance that leads to the achievement of objectives of the organization. This will help the organization to keep a competitive position in the corporate world.

\section{A. Practical Implications}

The study provides valuable information to the top management of organizations that handling the employees carefully will enhance their efforts towards obtaining the goals. It 
also helpful for leaders to recognize the importance and difference between different emotional labor strategies and leaders can align these strategies with organizational goals and subordinates' needs (Boss \& Sims, 2008). Leaders with emotional intelligence abilities can make room for mental and physical space for the emotions ventilation at the workplace (Haver et al., 2013). This study provides direction to organizations to invest in training their leaders regarding the effective management of their emotions with theoretical and practical perspectives. Through training, an organization can also strengthen the basic abilities and skills to express naturally felt the emotion which can lead to improve job performance (Ong et al., 2006).

\section{B. Limitations \& Future Directions}

The study has many limitations. To make this research more valuable, other dimensions of POS and Emotional Labor like display of genuine emotion can be added. Furthermore, time and sample size are also a constraint. Future researchers can expand the sample size. Data can be collected from other sectors also. More concise demographic analysis can help to find results more accurately. Similarly, the longitudinal study can be designed in future. 


\section{References}

Ahmad-Mughal, S., Nisar, Q. A., Othman, N., \& Kamil, B. A. M. (2017). Do Emotional Intelligence \& Organizational Politics influence the Employee Work Behaviors and attitudes? Mediating Role of Political Skill. Jurnal Pengurusan, (51).

Allen, J. A., Pugh, S. D., Grandey, A. A., \& Groth, M. (2010). Following display rules in good or bad faith?: Customer orientation as a moderator of the display rule-emotional labor relationship. Human Performance, 23(2), 101-115

Anderson, N., Ones, D. S., Sinangil, H. K., \& Viswesvaran, C. (Eds.). (2001). Handbook of industrial, work \& organizational psychology: Volume 1: Personnel psychology. Sage.

Aubé, C., Rousseau, V., \& Morin, E. M. (2007). Perceived organizational support and organizational commitment: The moderating effect of locus of control and work autonomy. Journal of managerial Psychology, 22(5), 479-495.

Barrett, A., \& O'Connell, P. J. (2001). Does training generally work? The returns to incompany training. ILR Review, 54(3), 647-662.

Berry, C. M., Ones, D. S., \& Sackett, P. R. (2007). Interpersonal deviance, organizational deviance, and their common correlates: A review and meta-analysis. Journal of applied psychology, 92(2), 410

Butt, S. S., Nisar, Q. A., Nadeem, S., \& Baig, F. (2017). Longitudinal study to examine the influence of emotional intelligence on organizational citizenship behavior: Mediating role of political skills. WALIA Journal, 33(1), 54-63.

Caruso, D. R., \& Salovey, P. (2004). The emotionally intelligent manager: How to develop and use the four key emotional skills of leadership. John Wiley \& Sons.

Caruso, D. R., \& Wolfe, C. J. (2001). Emotional intelligence in the workplace. Emotional intelligence in everyday life, 150-167.

Chou, R. J. A., \& Robert, S. A. (2008). Workplace support, role overload, and job satisfaction of direct care workers in assisted living. Journal of Health and Social Behavior, 49(2), 208-222.

Dimitriades, Z. S. (2007). Managing emotionally intelligent service workers: Personal and positional effects in the Greek context. Journal of European Industrial Training, 31(3), 223-240.

Duke, A. B., Goodman, J. M., Treadway, D. C., \& Breland, J. W. (2009). Perceived organizational support as a moderator of emotional labor/outcomes relationships. Journal of Applied Social Psychology, 39(5), 1013-1034.

Eisenberger, R., \& Stinglhamber, F. (2011). Perceived organizational support: Fostering enthusiastic and productive employees. Washington, DC, US: American Psychological Association.

Eisenberger, R., Armeli, S., Rexwinkel, B., Lynch, P. D., \& Rhoades, L. (2001). Reciprocation of perceived organizational support. Journal of applied psychology, 86(1), 42.

Eisenberger, R., Huntington, R., Hutchison, S., \& Sowa, D. (1986). Perceived organizational support. Journal of Applied psychology, 71(3), 500.

Eisenberger, R., Lynch, P., Aselage, J., \& Rohdieck, S. (2004). Who takes the most revenge? Individual differences in negative reciprocity norm endorsement. Personality and Social Psychology Bulletin, 30(6), 787-799.

Eisenberger, R., Stinglhamber, F., Vandenberghe, C., Sucharski, I. L., \& Rhoades, L. (2002). Perceived supervisor support: Contributions to perceived organizational support and employee retention. Journal of applied psychology, 87(3), 565. 
Pakistan Journal of Humanities and Social Sciences, 6(4), 2018

Giardini, A., \& Frese, M. (2006). Reducing the negative effects of emotion work in service occupations: Emotional competence as a psychological resource. Journal of Occupational Health Psychology, 11(1), 63.

Goleman, D. (2001). An EI-based theory of performance. The emotionally intelligent workplace: How to select for, measure, and improve emotional intelligence in individuals, groups, and organizations, 1, 27-44.

Gosserand, R. H., \& Diefendorff, J. M. (2005). Emotional display rules and emotional labor: the moderating role of commitment. Journal of Applied Psychology, 90(6), 1256.

Greenberg, J. (1990). Employee theft as a reaction to underpayment inequity: The hidden cost of pay cuts. Journal of applied psychology, 75(5), 561.

Haider, S., Nisar, Q. A., Baig, F., \& Azeem, M. (2018). Dark Side of Leadership: Employees' Job Stress \& Deviant Behaviors in Pharmaceutical Industry. International Journal of Pharmaceutical Research \& Allied Sciences, 7(2).

Hayyat, U., Nisar, Q. A., Imran, M., \& Ikram, M. (2017). Consequences of Emotional Labor in Health Sector of Pakistan. International Journal For Research In Business, Management And Accounting, 3(6), 64-79.

Hofstede, G. (1984). The cultural relativity of the quality of life concept. Academy of Management review, 9(3), 389-398.

Hsu, B. F., Chen, W. Y., Wang, M. L., \& Lin, Y. Y. (2010). Explaining supervisory support to work-family conflict: The perspectives of guanxi, LMX, and emotional intelligence. Journal of Technology Management in China, 5(1), 40-54.

Hur, W. M., Won Moon, T., \& Jun, J. K. (2013). The role of perceived organizational support on emotional labor in the airline industry. International Journal of Contemporary Hospitality Management, 25(1), 105-123.

Imran, A., Ahmad, S., Nisar, Q. A., \& Ahmad, U. (2014). Exploring relationship among rewards, recognition and employees' job satisfaction: A descriptive study on libraries in Pakistan. Middle-East Journal of Scientific Research, 21(9), 1533-1540.

Johnson, H. A. M., \& Spector, P. E. (2007). Service with a smile: Do emotional intelligence, gender, and autonomy moderate the emotional labor process?. Journal of occupational health psychology, 12(4), 319.

Judge, T. A., Woolf, E. F., \& Hurst, C. (2009). Is emotional labor more difficult for some than for others? A multilevel, experience-sampling study. Personnel Psychology, 62(1), 57-88.

Kinman, G. (2009). Emotional labour and strain in "front-line" service employees: Does mode of delivery matter?. Journal of Managerial Psychology, 24(2), 118-135.

Konovsky, M. A., \& Pugh, S. D. (1994). Citizenship behavior and social exchange. Academy of management journal, 37(3), 656-669.

Krishnan, J., \& Mary, V. S. (2012). Perceived organisational support-an overview on its antecedents and consequences. International Journal of Multidisciplinary Research, 2(4), 2-3.

Lambert, S. J. (2000). Added benefits: The link between work-life benefits and organizational citizenship behavior. Academy of management Journal, 43(5), 801-815.

Lee, R. T., \& Brotheridge, C. M. (2011). Words from the heart speak to the heart: A study of deep acting, faking, and hiding among child care workers. Career Development International, 16(4), 401-420.

Lehman, W. E., \& Simpson, D. D. (1992). Employee substance use and on-the-job behaviors. Journal of applied Psychology, 77(3), 309.

Lou, J. H., Yu, H. Y., \& Chen, S. H. (2010). Factors affecting the career development of male nurses: a structural equation model. Journal of advanced nursing, 66(4), 900-910. 
Mastracci, S. H., Newman, M. A., \& Guy, M. E. (2010). Emotional labor: Why and how to teach it. Journal of Public Affairs Education, 123-141.

Modassir, A., \& Singh, T. (2008). Relationship of emotional intelligence with transformational leadership and organizational citizenship behavior. International journal of leadership studies, 4(1), 3-21.

Mubeen, H., Ashraf, H., \& Nisar, Q. A. (2016). Impact of emotional intelligence and knowledge management on organizational performance: Mediating role of organizational learning. Journal of Management Info, 11(2), 35-52.

Nisar, Q. A., Imran, A., Othman, N. B., Kamil, B. A. B. M., \& Marchalina, L. (2017). Do leaders' emotional labor strategies influence the leaders' emotional exhaustion? Moderating role of emotional intelligence: Longitudinal study on NGOs. Advanced Science Letters, 23(9), 8131-8137.

Nisar, Q. A., Marwa, A., Ahmad, U., \& Ahmad, S. (2014). Impact of perceived organizational support on organizational citizenship behavior: Empirical evidence from Pakistan. International Journal of Research, 1(5), 231-240.

Perlow, R., \& Latham, L. L. (1993). Relationship of client abuse with locus of control and gender: A longitudinal study in mental retardation facilities. Journal of Applied Psychology, 78(5), 831.

Purcell, J. (2003). Understanding the people and performance link: Unlocking the black box. CIPD Publishing.

Rhoades, L., \& Eisenberger, R. (2002). Perceived organizational support: a review of the literature. Journal of applied psychology, 87(4), 698.

Rhoades, L., Eisenberger, R., \& Armeli, S. (2001). Affective commitment to the organization: The contribution of perceived organizational support. Journal of applied psychology, 86(5), 825.

Riggle, R. J., Edmondson, D. R., \& Hansen, J. D. (2009). A meta-analysis of the relationship between perceived organizational support and job outcomes: 20 years of research. Journal of business research, 62(10), 1027-1030.

Robinson, S. L., \& Bennett, R. J. (1995). A typology of deviant workplace behaviors: A multidimensional scaling study. Academy of management journal, 38(2), Simosi, M. (2012). Disentangling organizational support construct: The role of different sources of support to newcomers' training transfer and organizational commitment. Personnel Review, 41(3), 301-320.

Salovey, P., Mayer, J. D., Goldman, S. L., Turvey, C., \& Palfai, T. P. (1995). Emotional attention, clarity, and repair: Exploring emotional intelligence using the Trait MetaMood Scale.

Shore, L. M., \& Shore, T. H. (1995). Perceived organizational support and organizational justice. Organizational politics, justice, and support: Managing the social climate of the workplace, 149-164.

Singh, K. (2010). Developing human capital by linking emotional intelligence with personal competencies in Indian business organizations.

Spector, P. E., Fox, S., Penney, L. M., Bruursema, K., Goh, A., \& Kessler, S. (2006). The dimensionality of counterproductivity: Are all counterproductive behaviors created equal?. Journal of vocational behavior, 68(3), 446-460.

Tang, C., Seal, C. R., Naumann, S. E., \& Miguel, K. (2013). Emotional labor: The role of employee acting strategies on customer emotional experience and subsequent buying decisions. International Review of Management and Marketing, 3(2), 50. 
Tharenou, P., Saks, A. M., \& Moore, C. (2007). A review and critique of research on training and organizational-level outcomes. Human Resource Management Review, 17(3), 251-273.

Westbrook, T. M., \& Crolley-Simic, J. (2012). Perceptions of administrative and supervisory support in public child welfare. Advances in Social Work, 13(3), 603-617.

Wong, C. S., \& Law, K. S. (2002). The effects of leader and follower emotional intelligence on performance and attitude: An exploratory study. The leadership quarterly, 13(3), 243-274.

Wong, C. S., Law, K. S., \& Wong, P. M. (2004). Development and validation of a forced choice emotional intelligence measure for Chinese respondents in Hong Kong. Asia Pacific Journal of Management, 21(4), 535-559.

Wong, C. S., Wong, P. M., \& Law, K. S. (2007). Evidence of the practical utility of Wong's emotional intelligence scale in Hong Kong and mainland China. Asia Pacific Journal of Management, 24(1), 43-60.

Zhou, J., \& George, J. M. (2003). Awakening employee creativity: The role of leader emotional intelligence. The leadership quarterly, 14(4-5), 545-568.

Zia ur Rehman, M., Khan, M. R., \& Ali Lashari, J. (2008). Effect of Job Rewards on Job Satisfaction, Moderating Role of Age Differences: Emperical Evidence from Pakistan. 